\title{
La fortificación del estrecho de Magallanes: un proyecto al servicio de la imagen de la monarquía
}

\author{
Joaquín ZULETA CARRANDI \\ GRISO - Universidad de Navarra \\ jzuleta@alumni.unav.es
}

Recepción: 6 de noviembre de 2012 / Revisión: 3 de febrero de 2012 Aceptación: 12 de febrero de 2012 / Publicación: diciembre de 2013

\section{RESUMEN}

En estas páginas me ocupo de la descripción del proyecto de fortificación del estrecho de Magallanes (1581), tomando en cuenta nuevas fuentes documentales y criticando las ya conocidas. El contexto que me interesa analizar es el proceso de transformación que sufre el proyecto fortificador durante su debate en España. Sostengo que es necesario interpretarlo como parte del aparato de propaganda de la monarquía hispánica.

Palabras clave: Estrecho de Magallanes, Pacífico, Chile, fortificaciones, Sarmiento de Gamboa, Drake, Antonelli, siglo XVI, Felipe II, Spannocchi.

\section{The Fortification of the Strait of Magellan: Project for the Image of the Monarchy}

\begin{abstract}
These pages are dedicated to providing a description of the fortification project for the Strait of Magellan (1581), considering new sources and offering a critique of the traditional ones. The context analyzed is the process of transformation of the fortification project as a result of its debate in Spain. I maintain that it ought to be interpreted as part of the propagandistic apparatus of the Spanish Monarchy.
\end{abstract}

Key words: Strait of Magellan, Pacific, Chile, Fortifications, Sarmiento de Gamboa, Drake, Antonelli, $16^{\text {th }}$ Century, Philip II of Spain, Spannocchi.

Sumario: 1. Introducción. 2. Crítica de fuentes. 3. El proyecto fortificador en su primera etapa. 4. Oposición al proyecto. 5. Imagen de la monarquía. 6. Conclusiones. 7. Referencias bibliográficas. 
Ma'come di saette ardori ha l'Arme

Cosi chiaro Antonelli hor vi disegna e apparechia qua giu fulmin di guerra Acciò 'l uostro terreno Imperio s'arme Di simil forsa, et sappia ogn'un che regna Un Giove in ciel, et un Filippo in terra.

Alessandro Spinola

\section{INTRODUCCIÓN}

En 1581 la administración de los Austrias emprende el proyecto de fortificación del estrecho de Magallanes. Esta curiosa iniciativa se inscribe en el extenso programa de fortificaciones llevado a cabo en España y América durante la segunda mitad del siglo XVI. Si bien podemos interpretar toda fortaleza como imagen de autoridad real, el cierre del estrecho de Magallanes tiene connotaciones muy particulares en lo que respecta al poder técnico y la visión geoestratégica del reinado de Felipe II ${ }^{1}$.

Me interesa describir y analizar el proyecto de fortificación del estrecho, cuya figura más importante es el descubridor gallego Pedro Sarmiento de Gamboa, quien hasta entonces había desempeñado las funciones de explorador, cosmógrafo, historiador y soldado en el virreinato del Perú2 ${ }^{2}$ Sarmiento llega a España en 1580, enviado por el virrey Francisco de Toledo, luego de una travesía por el estrecho de Magallanes en búsqueda de los corsarios ingleses liderados por Francis Drake. En 1578, el Golden Hind logró atravesar el estrecho, asaltando varias villas en el Pacífico y atacando el Cacafuego, un pequeño galeón que transportaba parte del tesoro desde el Perú a Panamá. Este golpe proporcionó a Drake un riquísimo cargamento de barras de plata ${ }^{3}$. Los corsarios regresan a Inglaterra por la ruta portuguesa: Molucas y el cabo de Buena Esperanza, completando la segunda circunnavegación del globo.

El virrey Francisco de Toledo envía a Pedro Sarmiento de Gamboa con un doble propósito: capturar a Drake, en caso de que su flota hubiese elegido el mismo camino para volver a Inglaterra; y además, explorar el estrecho de Magallanes, con especial atención a las "bocas del Estrecho", pensando ya en la construcción de uno o dos fuertes que impidiesen la presencia de corsarios en aguas del Pacífico.

Pedro Sarmiento es el primer navegante en realizar el derrotero entre el Perú y Europa pasando por el estrecho de Magallanes. Una vez llegado a España, Sarmiento se presenta ante el Felipe II, en Tomar, donde tendría lugar su juramento como rey de Portugal. El monarca aprueba el proyecto de fortificación y se propone enviar una gran flota: la Ar-

1 La relación entre fortificación y propaganda en los Siglos de Oro ha sido ampliamente estudiada por Hernando SÁnchez, 2001, pp. 21-91 y CÁMARA, 1998.

2 Forma parte, junto a Álvaro de Mendaña, de la expedición que va en descubrimiento de las islas de Salomón; escribe la Historia Índica; participa en la visita general al Perú organizada por el virrey Toledo y combate en la campaña contra los indios chiriguanos. BARRos, 2006, pp. 37-70.

3 KelSEY, 1998, pp. 156-162. Sarmiento de Gamboa ofrece una completa versión de los hechos: "Relación de lo que el cosario Francisco hizo y robó en la costa de Chile y Pirú, y las diligencias que el virrey don Francisco de Toledo hizo contra él". Lima, 1579. Archivo Zabálburu, Altamira, 2/33.

4 Instrucción al capitán Pedro Sarmiento de Gamboa. Ciudad de los Reyes, 9-X-1579. Archivo General de Indias (en adelante AGI), Patronato, 33, N. 2, R. 6. 
mada del Estrecho ${ }^{5}$, cuyo responsable, el general Diego Flores de Valdés, es tristemente célebre por su papel en la derrota de la Armada Invencible siete años después de los hechos que nos ocupan 6 .

La empresa de fortificación y población tuvo un final muy desgraciado: después de un viaje largo y accidentado, poco más de 300 colonos logran llegar al estrecho de Magallanes y fundar dos poblaciones. Prácticamente todos murieron por inanición y de ahí que el corsario Thomas Cavendish bautizara la Ciudad del Rey don Felipe como Port Famine, Puerto de Hambre, en su paso por el estrecho el año $1587^{7}$.

Por su parte, Sarmiento de Gamboa regresa al Brasil y más tarde intenta volver a España en busca de ayuda para las precarias poblaciones del estrecho. Es capturado por corsarios ingleses y llevado preso a Inglaterra. Una vez liberado por intercesión de Isabel Tudor, pasa tres años prisionero en Francia - esta vez en manos de los hugonotes- para finalmente llegar a España en 1590. Muere en Lisboa dos años después ${ }^{8}$.

Es muy importante tener presente el contexto político de España en 1581: Felipe II, sucesor del trono de Portugal y sus colonias en Asia y América, se convertía en el monarca con mayores territorios en la historia de la humanidad ${ }^{9}$. Resulta comprensible, según ha señalado Parker, que la principal preocupación de la monarquía hispánica fuera la defensa $\mathrm{y}$ conservación de los territorios heredados ${ }^{10}$. Así, el proyecto de fortificar el estrecho de Magallanes formaba parte de la política defensiva de Felipe II.

\section{CRÍTICA DE FUENTES}

El estado actual de los estudios sobre el intento de fortificación del estrecho de Magallanes no permite hacer un análisis preciso respecto de las implicaciones culturales y simbólicas de lo que se entendía por clausura del Pacífico. Si bien la crítica ha hecho importantes esfuerzos de interpretación de las fuentes, existe todavía una arraigada confusión en la datación de algunos documentos y un completo desconocimiento del proceso que sufre el proyecto de Sarmiento a través de la década de 1580. Mi propuesta es la siguiente: debemos entender el proyecto fortificador en dos etapas muy distintas, que se corresponden

5 El nombre de "Armada del Estrecho" o "Armada de Magallanes" era usado sólo entre los miembros del Consejo de Guerra. Copia de carta que su majestad escribió a don Francés de Álava. Lisboa, 25-II-1581. Archivo General de Simancas (en adelante AGS), Guerra y Marina (en adelante GM), 111/252. Para no divulgar los objetivos finales de la armada, en los documentos oficiales se utilizó el nombre de "Armada para la seguridad y guarda de nuestras Indias" o "Armada del cargo del general Diego Flores". Instrucción a Antón Pablos. Lisboa, 27-VIII-1581. AGI, Chile, 165, L. 2, fol.7r.

6 No contamos con un trabajo monográfico exhaustivo sobre la Armada del Estrecho por parte de la historiografía naval española o americana. El tema ha sido tratado por MARTINIC, 1977 y 1992; OyARZúN IÑARRA, 1976; O'DonNell, 1992; SANTOS, 1993, BENITES, 2004, entre varios otros. Respecto a la actuación de Diego Flores de Valdés en la empresa de Inglaterra ver Tellechea Idígoras, 1988, pp. 593-596 y Parker, 2010 , p. 854.

7 MARTINIC, 1977, p. 69. El Instituto de la Patagonia de la Universidad de Magallanes ha emprendido varias excavaciones arqueológicas en la zona: MARTINIC, 1983. Respecto de los hallazgos arqueológicos en territorio argentino, ver De Nigris - SENATORE, 2008.

8 Existen varias biografías de Sarmiento de Gamboa: Landín CARRASCo, 1945; ArCiniega, 1956 y Barros, 2006.

9 Respecto a la sucesión de Portugal, ver Bouza Álvarez, 1987; Valladares, 2008.

10 PARKER, 1998, pp. 31-45. 
con los momentos anterior y posterior del viaje de la Armada del Estrecho. La primera etapa hay que situarla en el año 1581 y la segunda en 1590. Esta tesis está sustentada por una reinterpretación de las fuentes conocidas y por la consulta de nueva documentación, proveniente del Archivos General de Indias y del Archivo de Simancas.

El proyecto fortificador y poblador de Sarmiento de Gamboa ha sido tratado por varios estudiosos: Martín Fernández de Navarrete, Julio Guillén Tato, Ángel Rosenblat, Gabriel Guarda y Eduardo Nussio Díaz, entre otros. A los dos primeros tenemos que reconocer el hallazgo de los documentos. Al resto debemos la labor divulgativa del tema y los primeros intentos de interpretación de las fuentes.

En 1793 Fernández de Navarrete localiza en el Archivo de Indias la "Instrucción para los fuertes del estrecho de Magallanes" ${ }^{\prime 1}$. Este documento, firmado por Tiburcio Spannocchi, describe los fuertes proyectados en el estrecho, en su punto más angosto; se refiere a la topografía de la Primera Angostura -llamada por Sarmiento angostura de Nuestra Señora de la Esperanza-; detalla varios aspectos relativos a los materiales, mano de obra y los costes de la empresa. La Instrucción menciona unas "trazas" que servían de apoyo a las descripciones verbales. El mismo Fernández de Navarrete apunta que "las trazas o figuras que aquí se cita no se han encontrado" y data el documento en 1581, año de preparación de la Armada del Estrecho.

Figura 1. Diseño de los fuertes del estrecho de Magallanes, por Tiburcio Spannocchi.

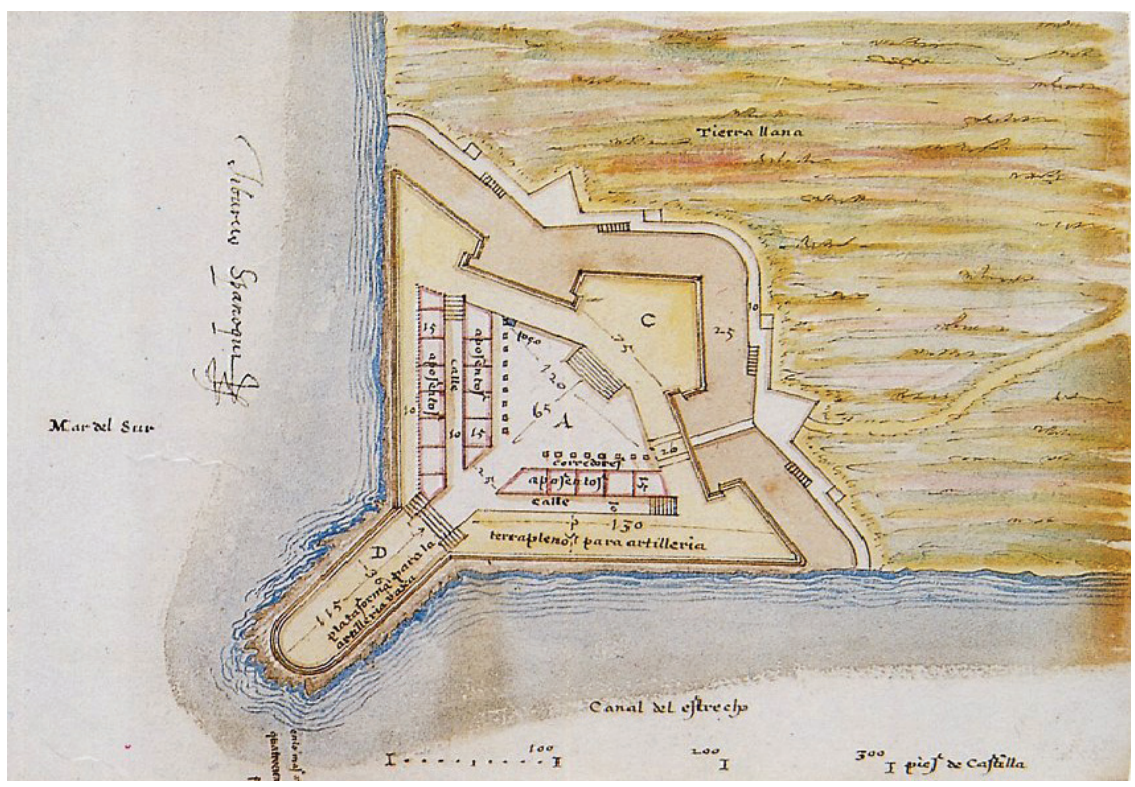

Fuente: Archivo del Museo Naval, Navarrete 20/139.

11 Instrucción de Tiburcio Spannocchi: construcción de castillos. AGI, Patronato, 33, N. 3, R. 6. La edición facsímil de la trascripción está en FERNÁNDEZ DE NAVARRETE, 1971, pp. 267-272. La instrucción ha sido editada por Rosenblat, véase Sarmiento de Gamboa, 1950, II, pp. 302-304. 
Pues bien, las trazas fueron halladas en 1940, en el Museo Naval de Madrid, por el almirante Julio Guillén Tato (Figura 1). Se trata de un plano con los diseños de las fortalezas que debían bloquear la entrada al estrecho de Magallanes. En reiteradas ocasiones la crítica ha considerado que el diseño de los fuertes del estrecho es un trabajo en colaboración de Tiburcio Spannocchi y Juan Bautista Antonelli ${ }^{12}$. Existen, sin embargo, argumentos biográficos y documentales que obligan a descartar esta idea. Tiburcio Spannocchi, quien mucho después llegaría a ser el "ingeniero mayor de los reinos de España", era en 1581 un recién llegado a la península. Había sido examinado en febrero del año anterior por Francisco de Ibarra, quien lo encontró muy hábil en "designios", pues era el italiano un experto dibujante, pero con poca práctica y ninguna experiencia en el campo de batalla, condición imprescindible para todo ingeniero militar ${ }^{13}$. Sabemos que en 1581 Spannocchi se encontraba ocupado en la fortificación de Fuenterrabía y es cierto que su nombre aparece entre los posibles candidatos para diseñar y construir los fuertes del estrecho ${ }^{14}$, pero no existe ningún documento que acredite su participación en esta fase del proyecto. Entre Juan Bautista Antonelli y Tiburcio Spannocchi nunca se dio, respectivamente, la relación de subalterno y jefe: no es posible que los diseños hayan sido trazados por Antonelli y firmados por Spannocchi. Lo cierto es que el documento que llamamos "Diseño de los fuertes del estrecho de Magallanes" pertenece por entero a Tiburcio Spannocchi. El trazo, la letra y la paleta de colores nos confirman este hecho ${ }^{15}$.

Además de los diseños de las fortalezas, Guillén Tato localiza un mapa de la boca oriental del estrecho, dibujado supuestamente por Sarmiento de Gamboa ${ }^{16}$ (Figura 2). Esta atribución es también un error que se ha repetido en varias ocasiones. Para salvar los riesgos, algún autor se refiere al mapa "que se imputa a Sarmiento", cuando en realidad se trata de un dibujo de Spannocchi ${ }^{17}$. Tanto la letra del mapa y como la del diseño de los fuertes resultan inconfundibles. Spannocchi comunica, a través de la letra, su vinculación a la tradición renacentista florentina: se trata de una humanística redonda, angulada, con ligaduras en los grupos $s t, s p$; los caídos de las letras $s, f, h$,

12 Así lo han entendido Braun Menéndez, 1969, pp. 9-10; Nussio Díaz, 1999, p. 250 y 2001, p. 80.

13 CÁmARA, 1988, p. 77. Respecto a la formación de los ingenieros, ver CÁmARA, $2004 b$.

14 Francés de Álava nombra a Jorge Setara, Bautista Antonelli, Felipe Tercio y "Tiburcio, que es el que vuestra majestad envió a Fuenterrabía" como posibles candidatos para diseñar los fuertes del estrecho, aunque la "suficiencia de las personas nombradas no la tengo por tan cumplida que alcance a todo lo que se requiere porque no los he penetrado ni entendido que hayan hecho cosa de tanto momento". Carta de Francés de Álava a Felipe II. Lisboa, 9-III-1581. AGS, GM, 110/218.

15 Antonelli utiliza una letra humanística cursiva, de trazo ligero, muy distinta de la de Spannocchi. Además, aquel es aficionado a proyectar los edificios en perspectiva, dándoles un vistoso relieve; mientras que Spannocchi prefiere la proyección en planta. Ambos rasgos, letra y dibujo de Antonelli, podemos observarlos en, Prospectiva de Mazalquivir dibujada por Juan Bautista Antonelli a partir del proyecto de Vespaciano Gonzaga. 1574. AGS, Mapas, Planos y Dibujos (en adelante MPD), 7/103. El diseño está disponible en http:// www.mcu.es/ccbae/es/consulta/registro.cmd?id=178973 (Consultado el 4-X-2012).

16 El diseño de los fuertes y el mapa fueron publicados por primera vez en GuILLÉn TATO, 1942. Respecto a la atribución de la autoría del mapa, ver GuILlÉn TATO, 1944, p. 16.

17 Nussio Díaz y Zapatero no se atreven a declarar que la carta del estrecho fue realizada por Spannocchi a partir de las informaciones que le proporciona Sarmiento (Nussio DíAZ, 1999, p. 249; ZAPATERO, 1977 , p. 711). Cruz Almeida, si bien acierta, no deja de ser dubitativo: "Parece que Sarmiento de Gamboa colaboró con Tiburcio Spannocchi para el diseño de esta imagen cartográfica del estrecho de Magallanes”, Cruz AlmeIDA, 2010, pp. 216-217. 
alargados y curvados; los astiles de las $s$ y $f$, rectos y con forma de estrella ${ }^{18}$. La letra de Spannocchi - de trazo grueso, estilizado, elegante- y el uso de mayúsculas latinas, no tienen nada que ver con la letra de Juan Bautista Antonelli o con la de Sarmiento de Gamboa. Tanto la paleta de colores como la simbología gráfica resultan asimismo inconfundibles.

Figura 2. Mapa de la boca oriental del Estrecho de Magallanes, por Tiburcio Spannochi.

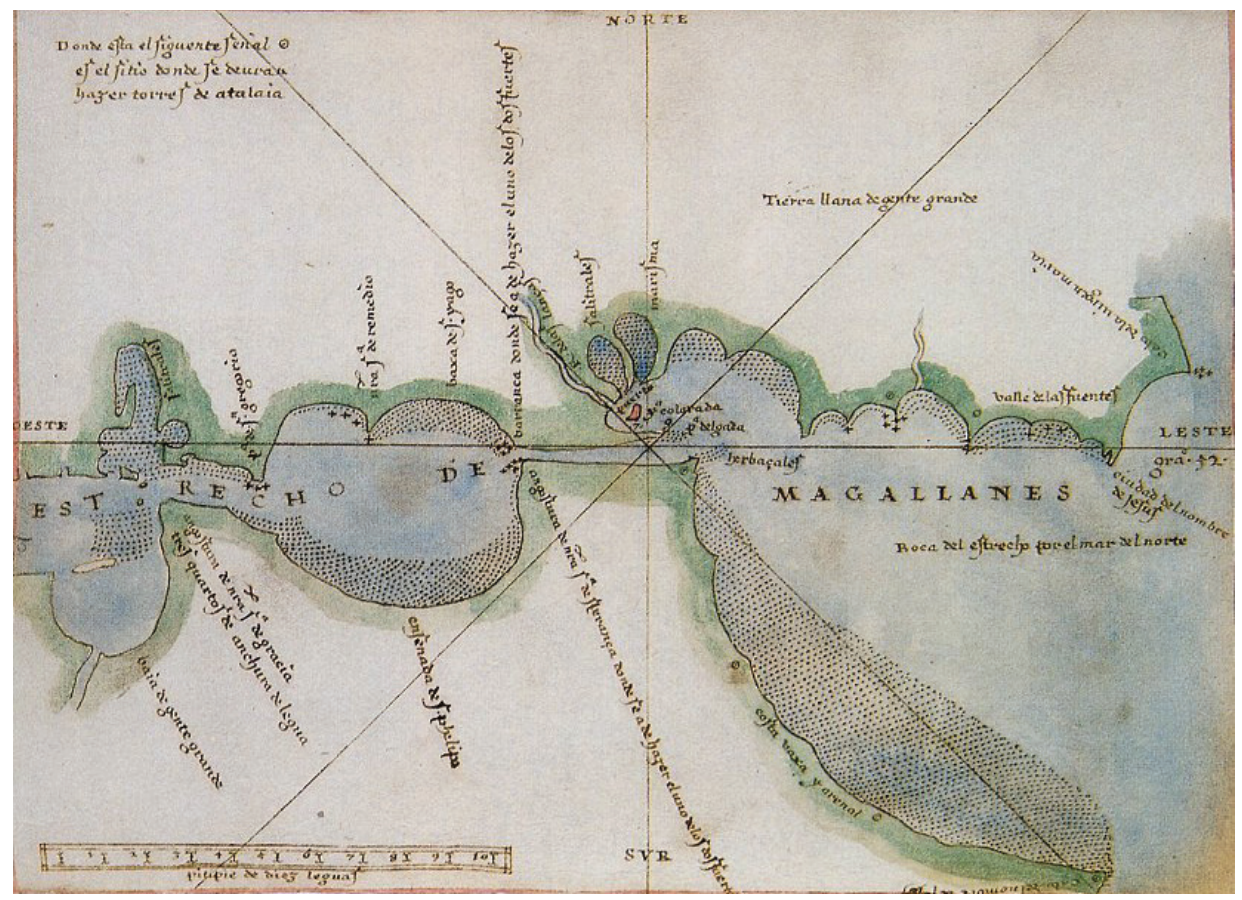

Fuente: Archivo del Museo Naval, Navarrete 20/137.

Tienen razón los estudiosos cuando apuntan que el mapa es posterior al año 1584, ya que Spannocchi incluye, además de varios topónimos del segundo viaje de Sarmiento, a la Ciudad del Nombre de Jesús, fundada en febrero de ese mismo año ${ }^{19}$.

El problema de fondo es el siguiente: hasta ahora se ha hablado de un único momento en el proyecto, aglutinando forzosamente todos los documentos en torno a 1581 . Mi propuesta es que existen dos etapas perfectamente identificables en el proyecto de fortificación del estrecho de Magallanes. La primera corresponde al año 1581, en que participa exclusivamente Juan Bautista Antonelli (y luego, como veremos, su hermano Bautista). La segunda etapa la situamos 10 años después y el único ingeniero

18 Las características de la humanística redonda y su vinculación con el renacimiento italiano en GALENDE DíAz, 1998, pp. 210-212.

19 Guarda, 1990, p. 53; Nussio Díaz, 1999, p. 252. 
involucrado es Tiburcio Spannocchi. Mientras el primer momento está marcado por la preparación de la Armada del Estrecho, cuyo principal objetivo era la fortificación, el segundo tiene que ver con la insistencia de Sarmiento de Gamboa por regresar una vez más al estrecho y continuar el malogrado proyecto. En ninguno de estos documentos de Spannocchi ("Instrucción", "Diseño de los fuertes" y "Mapa de la boca oriental del estrecho") figura la fecha de producción. Propongo que los documentos de Spannocchi no pueden ser considerados en un estudio del proyecto de fortificación en su primera etapa.

Las circunstancias biográficas de Sarmiento eran las siguientes: después de ser liberado por sus captores en Francia, regresa a España a mediados de $1590^{20}$. El desafortunado navegante elabora una serie de documentos para justificar su desempeño en la Armada del Estrecho; eximirse de toda responsabilidad en el fallido intento fortificador, y solicitar los medios para la prosecución del proyecto y auxilio a los pobladores ${ }^{21}$. Ya muerto Juan Bautista Antonelli, aliado fundamental del proyecto en su primera etapa, Sarmiento asiste, probablemente, a una entrevista con Tiburcio Spannocchi, a la sazón uno de los ingenieros más importantes de España. El resultado de este encuentro podemos verlo en los tres documentos en cuestión.

Hay varios argumentos a los que podemos recurrir para datar la instrucción de Spannocchi en torno a 1591:

A) El primer elemento que llama la atención de la instrucción de Spannocchi es que está escrita en un español bastante correcto, lo que nos lleva a sospechar que 1581 es una fecha demasiado temprana para datar el documento. Efectivamente, el ingeniero demuestra en su instrucción una soltura con la lengua que llevaba usando ya por más de 10 años, diferente de su español vacilante de $1581^{22}$.

B) El preciso conocimiento de la topografía del estrecho que se trasmite en la instrucción: Spannocchi sabe exactamente cómo es el lugar de emplazamiento de los fuertes. Esta información no fue recabada en el primer viaje de Sarmiento al estrecho ${ }^{23}$. La falta de información detallada respecto de los emplazamientos fue, de hecho, la causa de que en 1581 el famoso ingeniero Fratín ${ }^{24}$ declinara su participación en el proyecto ${ }^{25}$.

20 BARros, 2006, p. 161.

21 El documento más importante de esta nueva tentativa es la Sumaria relación. El Escorial, 15-IX-1590. AGI, Patronato, 33, N. 3, R. 68. El texto ha sido editado por Rosenblat y por SARABia Viejo, véase SARMIENTo DE GAMBOA, 1950 y 1988.

22 "Yo envié a su majestad, como creo que vuestra señoría haya ya recebido, los deseños desta fortaleza, y con ellos una menuda relación en escrito del todo lo cual estaba puesta en italiano porque con más facilidad digo mis pensamientos en mi materna lingua que no es esta castillana y después, considerado mejor, hame parecido bien enviar el mismo parecer en castillano, el cual sé que no será esprimido con la facilidad y buenas palabras que convernía, pero a lo mejor entendido". Carta de Spannocchi a Juan Delgado. S.1, 6-I-1581. AGS, GM, 110/22.

23 Después de su primer viaje, Sarmiento informa sobre el ancho, largo y orientación de la angostura. Respecto al terreno se limita de apuntar: "barranca por una parte y por la otra". SARMIENTO DE GAMBOA, 1950, I, p. 122 .

24 De procedencia italiana, Giacomo Palearo "el Fratín" fue de uno de los ingenieros militares más importantes de Felipe II. La obra que le da fama universal es la ciudadela de Pamplona. Ver VigANÒ, 2004.

25 "Con el Fratín se ha tratado aquí de si se podría hacer algún designo o traza de los fuertes; y no parece que es posible por no haber acá relación particular ni distinta de los sitios como para esto conviniere”. Copia 
En el segundo viaje al estrecho, Sarmiento tuvo la oportunidad de explorar detenidamente el lugar de emplazamiento de la fortaleza norte, en la marcha que hace desde Ciudad del Nombre de Jesús hacia la bahía donde sería fundada Ciudad del Rey don Felipe, en marzo de 1584:

Llegados a la Primera Angostura, donde se debía fortificar, desde tierra la reconocimos ser muy a propósito. Y hay a cuarto de legua una dehesa de más de cuatro leguas de largo y redonda, cosa de grande recreación de yerbas para ganado, viciosísima y lagunas y leña ${ }^{26}$.

Estos datos serán integrados por Spannocchi en sus diseños. Lo que Sarmiento llama "dehesa" es anotado como "tierra llana" por el italiano, acorde con el valor militar del territorio que Sarmiento describe con ojos de poblador (Spannocchi usa la expresión "tierra llama" en los tres documentos referidos). La dehesa que Sarmiento describe como "grande recreación de yerbas para ganado, viciosísima" fue bien representada por Spannocchi mediante abundantes pastos de varios colores. Ni el diseño de los fuertes ni la instrucción podrían haber sido tan detallados en 1581.

C) Tomemos en cuenta que durante la preparación de la Armada del Estrecho las medidas de la Primera Angostura no estaban en discusión. Se aceptaron los números que dio Sarmiento: tres leguas de largo y "de ancho menos de media legua" ${ }^{27}$, unos 2500 metros, cifra bastante precisa. Sin embargo, la anchura del estrecho fue uno de los argumentos que dieron los miembros de la Armada del Estrecho para justificar el abandono de empresa fortificadora: la distancia entre los fuertes sería mucho mayor de lo que había informado Sarmiento, de modo que resultaría inútil cualquier fortaleza. La cifra del ancho de la Primera Angostura según el almirante Diego de la Rivera, más de 7000 metros, manifiesta la imposibilidad de que la artillería alcanzase a los barcos enemigos que intentaran pasar el estrecho ${ }^{28}$. Así, los miembros de la armada justificaron el abandono de la empresa mediante una campaña de desprestigio sobre las posibilidades defensivas del canal. Esta discusión continuó en España. El Consejo de Indias, en 1585, hizo un interrogatorio a los miembros de la expedición, pidiendo explicaciones sobre el incumplimiento de la voluntad del rey ${ }^{29}$. La discusión en torno a las dimensiones del estrecho se reactivó cuando Pedro Sarmiento llega a España en $1590^{30}$.

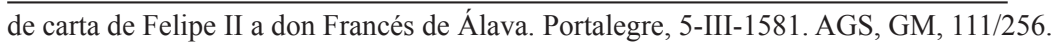

26 Sarmiento de Gamboa, 1950, II, p. 144.

27 Sarmiento de Gamboa, 1950, I, p. 122.

28 Sarmiento hizo redactar un documento para contradecirle: Probanza hecha por Pedro Sarmiento de Gamboa. Río de Janeiro, 13-VII-1584. AGS, Patronato, 33, N. 3, R. 38 (5). En la relación que dio Diego de la Rivera al Consejo de Indias, en 1584, se informa que la Primera Angostura tiene, en su punto más estrecho, "al parecer de todos los que la vieron, más de una legua". Esta información resultaba devastadora para el porvenir de los pobladores, ya que cuestiona la viabilidad del proyecto. En el mismo documento hay una nota al margen del licenciado Gasca, integrante de la Junta de Puerto Rico: "Dice que la mayor angostura tiene de ancho una legua". Relación de lo que sucedió a Diego de la Rivera. 1584. AGI, Patronato, 33, N. 3, R. 43 (2).

29 Pésima administración de la armada de Diego Flores. Madrid, 1585. AGI, Patronato, 33, N. 3, R. 55.

30 "Y si a vuestra señoría se le ofreciere alguna dificultad o duda en lo tocante a la angostura del estrecho u otra cosa, prontamente se dará a vuestra señoría satisfacción auténtica, con que se pueda tomar resolución oportuna [...] El que hace entender al rey nuestro señor y a vuestra señoría que es imposible cerrarle por la 
Como vemos en el diseño de Spannocchi, los fuertes estarán contrapuestos, lo más cerca posible el uno del otro. Sarmiento y Spannocchi encuentran una solución a la polémica de la anchura del estrecho: hay que aprovechar unos arrecifes con tal de ganarle terreno al mar y poder acercar los fuertes mediante la "Plataforma para la artillería baja" de uno y otro fuerte. Una nota en el diseño nos demuestra esta particular preocupación: "en lo más, angostura de cuatrocientos cincuenta pasos" separarían una plataforma de otra ${ }^{31}$. Así, Sarmiento y Spannocchi se proponen vencer las dificultades y desconfianzas sembradas por los veteranos de la Armada del Estrecho ${ }^{32}$.

D) La instrucción de Spannocchi dedica varias explicaciones a los "aposientos" de los soldados, que podemos ver también en los diseños. Estas comodidades eran inexistentes en 1581: los cuarteles para los soldados aparecen por primera vez en los diseños del capitán Fratín a mediados de la década de 1580. Tal innovación ha sido estudiada por Pablo de la Fuente, quien se refiere a "la importancia de la actuación de Fratín en la plaza fuerte de Rosas, otra de las joyas de nuestro patrimonio fortificado, en donde proyectó los cuarteles de la ciudad, una experiencia pionera en su tiempo" 33 . En todo caso, los diseños de Fratín no se concretaron en edificaciones hasta la década siguiente, cuando se instala la discusión en Italia y España respecto de la inclusión de cuarteles al interior de las fortalezas, debido a los inconvenientes derivados de alojar a los soldados en las ciudades por cuenta de los habitantes, como se hacía hasta entonces ${ }^{34}$.

Los alojamientos de la ciudadela de Jaca, proyectados por Spannocchi en 1592, fueron los que finalmente se trasformarían en modelo para el resto de fortalezas ${ }^{35}$. Contaba con almacenes, una escalera para comunicar el corredor y sótanos, al igual que los cuarteles de los fuertes diseñados para estrecho ${ }^{36}$. La preocupación que muestra el ingeniero por la vertiente de aguas de los alojamientos y la construcción de

mucha distancia de la angostura, y también que no habrá nadie vivo allá, se puede creer d'él que es instigado del espíritu malo que quiere impedir el bien de la cristiandad española”. Carta de Sarmiento de Gamboa a Juan de Idiáquez. Octubre de 1590. AGS, Estado, 606/224.

31 Diseño de los fuertes del estrecho de Magallanes, por Tiburcio Spannocchi. Archivo del Museo Naval, Madrid, Navarrete, 20/139.

32 Esta discusión, como dijimos, ocupaba un lugar muy secundario en 1581. De hecho, por el memorial de Diego Flores de Valdés sabemos que en 1581 ni siquiera se planteaba como exigencia construir los fuertes frente a frente. Véase, Lo que parece a Diego Flores de Valdés que conviene al servicio de su majestad cerca de las seis barcas que se dice son necesarias para la fortificación y fuerza del estrecho de Magallanes. 4-V-1581. AGS, GM, 113/ 185.

33 De la Fuente, 2004, p. 100.

34 CÁmara, 1998, pp. 145-146.

35 Traza del castillo de San Pedro que se tiene empezado en la ciudad de Jaca, por Tiburcio Spannocchi. AGS, MPD, 38/92. Versión digital en http://www.mcu.es/ccbae/es/consulta/registro.cmd?id=180776. (Consultado el 4-I-2012).

36 "Si se pudieran hacer sótanos, como lo entiendo, hacerse han donde fueren más cómodos - debajo de los aposientos, para mayor salud- como el sitio lo pidiere", Instrucción de Tiburcio Spannocchi: construcción de castillos. AGI, Patronato, 33, N. 3, R. 6. La misma preocupación muestra en 1593, cuando el ingeniero insiste ante el conde de Portalegre para evitar la humedad de la isla Tercera: "Los sótanos son muy necesarios, así para la salud como para la comodidad del soldado; y tanto más debiéndose forzosamente sacar los cimientos, y aunque el sitio fuera enjuto y arenoso". Copia de la instrucción que el conde de Portalegre dio a Antón Coll para la fortificación de la Tercera y lo que sobre ella dice Tiburcio Spannocchi. Zaragoza, XI-1593. AGS, GM, $379 / 229$. 
sótanos bajo las habitaciones, para evitar el "húmedo de la tierra" ${ }^{37}$ en los fuertes del estrecho, es una actitud propia de los ingenieros militares a partir de la década de 1590. De esta forma, parece necesario descartar que un inexperto Spannocchi idease de la nada estos adelantos en 1581 .

En definitiva, los tres documentos en discusión: el diseño de los fuertes, el mapa de la boca oriental del estrecho y la instrucción pertenecen íntegramente a Tiburcio Spannocchi. Todos constituyen el mismo proyecto, forman un corpus unitario y fueron elaborados de manera simultánea. El mapa establece el sitio exacto de emplazamiento de los fuertes; los planos y la instrucción detallan las medidas, materiales y condiciones de las fortalezas. Los documentos fueron trazados después del regreso de Sarmiento de Gamboa a España, hacia 1591.

Sabemos que Sarmiento pasa al menos un año y medio haciendo gestiones para que se apruebe la organización de una nueva Armada del Estrecho (el segundo semestre de 1590 y casi todo el año 1591) ${ }^{38}$. El organismo encargado de analizar los memoriales y elevar sus peticiones al rey era la Junta de Puerto Rico ${ }^{39}$, creada en 1583 para "los fines de defensa contra los corsarios y ataques de flotas enemigas en las costas de las Indias" ${ }^{40}$. Probablemente, durante este año y medio, Sarmiento tuvo tiempo de entrevistarse con Spannocchi y solicitar el diseño de los fuertes. Para ese entonces el navegante contaba con un cabal conocimiento del terreno, era "un plático de la tierra" ${ }^{41}$, y sabía muy bien las dificultades logísticas y los costos de una empresa de este tipo.

El proyecto se pospuso indefinidamente, Sarmiento muere a mediados de 1592 y el sueño fortificador cae en el olvido ${ }^{42}$. La propuesta de Spannocchi fue archivada: una señal de indiferencia ante los papeles del italiano es que no fueron comentados. La instrucción consta de cuatro folios escritos a modo de consulta, o sea, dejando la columna izquierda en blanco para que el monarca pudiese añadir sus notas, cosa que no se hizo. Es probable que ni siquiera Sarmiento haya llegado a conocer estos documentos.

\section{EL PROYECTO FORTIFICADOR EN SU PRIMERA ETAPA}

La fortificación del estrecho de Magallanes en 1581 consistía en levantar dos fuertes en el punto más angosto del canal, lugar que ahora conocemos como Primera Angostura. Cada fuerte estaría provisto de artillería, con el objeto de hundir cualquier navío enemigo que intentara pasar. El apoyo logístico y la asistencia espiri-

\footnotetext{
37 Instrucción de Tiburcio Spannocchi: construcción de castillos. S.1, s.d. AGI, Patronato, 33, N. 3, R. 6

38 Memorial de Sarmiento de Gamboa a Felipe II. S.1, 21-XI-1591. AGI, Patronato, 33, N. 3, R. 68.

39 "Y vuestra majestad lo remitió a la Junta de Puerto Rico, donde los ministros della, con rara industria y diligencia, especularon -con intervención de Pedro Sarmiento- todas las dificultades que se les ofrecieron, de que Pedro Sarmiento satisfizo demostrativamente". Memorial de Sarmiento de Gamboa a Felipe II. S.1, 21-XI1591. AGI, Patronato, 33, N. 3, R. 68.

40 SCHÄFER, 1935, I, p. 170.

41 Instrucción de Tiburcio Spannocchi: construcción de castillos. S.1, s.d. AGI, Patronato, 33, N. 3 , R. 6. Plático es una variación de práctico, común en el siglo XVI, por 'experimentado, versado, diestro'.

42 Barros, 2006, pp. 163-165.
} 
tual de los fuertes estarían a cargo de las poblaciones que Sarmiento, nombrado gobernador, planificaba establecer a orillas del estrecho ${ }^{43}$.

El proyecto concentró la atención de la corte, el Consejo de Indias y la Casa de Contratación durante la mayor parte del año 1581. El envío de la armada tenía el carácter de urgente, ya que la diplomacia y el aparato de espionaje de los Austrias informaban de la preparación de flotas en Inglaterra, cuyo propósito consistía en alcanzar el Pacífico, bien para atacar puertos del virreinato del Perú, bien para comerciar con las Molucas ${ }^{44}$. Se decía además que los corsarios ingleses aspiraban a crear una colonia y fortificar el paso austral ${ }^{45}$. Así, el estrecho se transformó en un enclave geoestratégico que era necesario dominar por parte de España.

¿Qué sabemos del diseño de las fortalezas? Las primeras trazas para los fuertes, hechas por Juan Bautista Antonelli, no han sido encontradas. Sí contamos con la instrucción, documento que hasta ahora no ha sido considerado por los estudiosos. Antonelli propone un fuerte con cuatro baluartes: dos que miran hacia la tierra y dos hacia el mar ${ }^{46}$. Existe además una notable correspondencia de Felipe II y el duque de Alba que nos puede ayudar a imaginar las trazas del novedoso proyecto.

Como ya apuntó Alicia Cámara ${ }^{47}$, el modelo del proyecto defensivo lo encontramos en la desembocadura del río Tajo: Francés de Álava, capitán general de Artillería, hace notar la similitud topográfica de ambos lugares y propone construir dos fuertes, uno a cada orilla del estrecho, a imitación de la Torre de Belem y Torrevieja. El mismo Álava, sin embargo, detecta un problema en el modelo de defensa elegido: no resulta del todo eficaz para bloquear el paso a los navíos enemigos. La

43 "Donde estos fuertes se hicieren ha de haber dos pueblos de españoles, los cuales parece que son muy necesarios y que sin ellos en ninguna manera se puede esperar buen suceso; porque hacer fuerzas con soldados y gente de guerra entre indios que nuevamente se pretende que vengan al conocimiento de Dios y a obediencia de vuestra majestad sería poner quien los destruyese, robándoles y haciéndoles otras fuerzas y daños de los que los soldados suelen hacer, que aun en España, donde hay tanta justicia, hacen las insolencias y excesos que cada día se ven". Consulta del Consejo de Indias. Madrid, 1-III-1581. AGI, Indiferente, 739, N. 306.

44 Un personaje clave en las informaciones que recibía Felipe II era el embajador en Londres Bernardino de Mendoza, quien elabora entre 1578 y 1581 un buen número de cartas cifradas en las que advierte de los planes de los ingleses para ir hasta Molucas pasando por estrecho: "Que Conols, hijo del tesorero de la casa desta Reina, que es el que armó navíos para ir a robar a la carrera de las Indias agora dos años, vaya con seis a invernar a la costa del Brasil, en el puerto de San Julián, que es a la boca del estrecho de Magallanes y que de allí pase con la instrucción que lleva de Draques y algunos marineros que le acompañaron a la Mar del Sur, robando lo que pudiere, y después siga la derrota a juntarse en las islas de los Malucos con Draques, a dar la vuelta". Copia de carta descifrada de Bernardino de Mendoza a Felipe II. Londres, 9-I-1581. AGS, Estado, $835 / 208$

45 "Por los avisos que se han tenido de Francia e Inglaterra se ha entendido que se arman navíos de corsarios para ir a robar en las Indias y costas dellas; y que principalmente tienen su propósito de acudir al estrecho de Magallanes y apoderarse si pudieren d'él. Y porque este es negocio de mucha importancia, hemos acordado que se haga una armada tal que vase a estorbar estos disignios y a castigar a los dichos corsarios". Copia de carta de Felipe II a Francés de Álava. Lisboa, II-1581. AGS, GM, 111/52. Sabemos que existió un proyecto de fortificación por parte de los ingleses; el cosmógrafo Richard Hakluyt escribió un memorial intitulado: "A discourse of the commodity of the taking of the Strait of Magellanus", HAKLUYT, 1935, I, pp. 139-146.

46 Instrucción para el que ha de fabricar los dos fuertes que manda su majestad hacerse en el estrecho de Magallanes, llamado agora de la Madre de Dios, por Juan Bautista Antonelli. S.1, s.d. AGS, GM, 140/97. Este diseño fue criticado por el duque de Alba: Carta del duque de Alba a Felipe II. Jóbregas, 21-IV-1581. AGS, GM, 112/ 94.

47 CÁmARA, 1998, p. 70. 
solución estaría entonces, apunta Álava, en disponer una pequeña flota de navíos ligeros "para entretener y correr aquel estrecho" ${ }^{48}$. Estamos ante un modelo europeo de fortificación que va a requerir una serie de mejoras estructurales para resultar efectivo. La Torre de Belem seguirá funcionando como referencia para describir a las autoridades españolas las características del estrecho de Magallanes ${ }^{49}$.

A mediados de abril de 1581, con el objetivo de juzgar los diseños de Antonelli, Felipe II ordena la celebración de una junta conformada por el duque de Alba, don Francés de Álava y el marqués de Santa $\mathrm{Cruz}^{50}$. Ante ellos se presentan Sarmiento de Gamboa y el entonces influyente ingeniero Juan Bautista Antonelli, quien estaba teniendo un papel muy importante en la sucesión de Portugal ${ }^{51}$. Si bien a los miembros de la junta les parece un buen proyecto defensivo, las trazas de Antonelli fueron consideradas insuficientes. Dice el duque de Alba en carta al rey:

Yo no tengo por defendido el canal para estorbar que no pasen navíos por él con dos fuertes solos, porque la corriente es tan grande que los navíos que quisieren aventurarse a pasar lo harán de diez veces que se aventuren, las nueve, porque con la reciura de la corriente con que por allí entra la marea, el navío volará y será dicha que la artillería le toque [...] Si se pudieran hacer (al luengo del canal, de la estrechura hacia el levante, en las riberas del norte y del sur) fuertes que vinieran cañoneándose siempre los navíos por un luengo espacio, esto tuviera yo por muy buena guardia ${ }^{52}$.

El sistema defensivo que plantea el duque de Alba no existe en el siglo XVI. Deberán pasar muchos años para que se desarrolle la técnica de baterías en fortificaciones marítimas: una evolución de las torres y plataformas en forma de protecciones bajas, dotadas de artillería, que se ubican en la proximidad de las plazas con el objeto de dominar el exterior de la fortaleza y permitir mayor capacidad de maniobra. Con baterías se puede tirar desde muchos puntos y hacer fuego cruzado ${ }^{53}$.

La idea de las fortalezas sucesivas que soñaba el duque de Alba será una realidad recién a mediados del XVIII, cuando Ignacio Sala, gobernador de Cartagena, presente los estudios para la defensa del canal de Bocachica, que incluía "una pla-

\footnotetext{
48 Carta de Francés de Álava a Antonio de Eraso. Lisboa, 18-IV-1581. AGS, GM, 112/32.

49 "Este testigo se fue a proa y miró muy bien a la angostura y le pareció ser más angosto que de la Torre de Belem a la torrecilla, en Lisboa, y que conforme a esto, fortificando como su majestad manda no podrá pasar nao ninguna sin que se lo defiendan y echen a fondo". Probanza hecha por Pedro Sarmiento de Gamboa. Río de Janeiro, 13-VII-1584. AGI, Patronato, 33, N. 3, R. 38 (5).

50 Copia de Carta de Felipe II al duque de Alba. Tomar, 14-IV-1581. AGS, GM, 112/ 215.

51 Juan Bautista Antonelli, de origen italiano, entra al servicio de Felipe II a fines de la década de 1550, dando origen a la importante labor de la familia Antonelli en la fortificación de las costas España y América. Ver http:/www.provincia.fc.it/cultura/antonelli/ESP/ (Consultado el 4-X-2012). Juan Bautista Antonelli participa de forma activa en la política adoptada por los Austrias respecto de la sucesión de Portugal: se transforma en un destacado informante y asesor en todos los asuntos relacionados con las plazas fuertes portuguesas y con las nuevas fortificaciones del reino (SOROMENHO, 2004). Prepara, además, un ambicioso plan que permitirá conectar a toda la península ibérica: la navegación del río Tajo entre Toledo y Lisboa (CÁMARA, 1998, p. 213 y 2004a, pp. 213-216). Mucho antes de lograr una influencia relevante en las decisiones reales, Antonelli exhibía una notable veta como tratadista y memorialista, véase Discurso de Juan Bautista Antonelli dirigido a Felipe II. S.1, 1569. AGS, GM, 72/294 y 295.

52 Carta del duque de Alba a Felipe II. Jóbregas, 21-IV-1581. AGS, GM, 112/ 94.

53 Zapatero, 1978, pp. 113-130.
} 
taforma de 13 cañones para seguir la marcha de los navíos en el intento de penetración”, contrapuesta a la batería de Santa Bárbara, en la banda norte del canal, para "correspondencia de fuegos" 54 .

Retomemos el discurso del duque de Alba:

esto tuviera yo por muy buena guardia, pero siendo el canal que va por medio de los bajíos (en esta parte que yo digo) tan lejos de tierra, no se pueden hacer fuertes que alcancen a hacer este efecto. Y para remiendo desto me pareció (como ordené a Joan Baptista, que pusiese por memoria) que se hiciesen seis barcones grandes, chatos, como barcas de pasaje de ríos, tan gruesos y con maderas tan firmes que sufriesen un cañón en cada uno de d'ellos, que yo he traído algunos en canales de Holanda en que había dos cañones y se sufrían muy bien y los vi hacer grandes efectos; y que estos seis barcos, como se descubra el navío, suban por el canal, tres a una parte y tres a otra, distantes los unos y los otros más que tiro de arcabuz, por los bajíos donde los navíos que viniesen no puedan llegar a ellos. Y de aquella manera, comenzando a llegar el navío, comenzarán a saludarle los delanteros y vendrán acompañándole hasta los castillos, jugando siempre los barcones en los dichos navíos ${ }^{55}$.

El duque de Alba propone un sistema defensivo sin apenas precedentes. Se adelanta en al menos dos siglos a las tácticas de defensa militar. La barca o lancha cañonera, como se conocerá a los barcones dotados de un cañón, data de fines del XVIII: fue usada con relativo éxito en la expedición a Argel en 1775 y más tarde en el bloqueo a Gibraltar ${ }^{56}$. Su invención se atribuye al capitán general de Marina don Antonio Barceló ${ }^{57}$. En América funcionaron con mucha efectividad en el Callao ya en la segunda mitad del XVIII y fueron usadas en batallas de las independencias americanas $^{58}$.

Hasta aquí se ha hablado de una fortaleza en ambas orillas del estrecho, cada una bien provista de artillería, además de seis barcones encargados de rodear y abrir fuego contra la flota enemiga que intenta superar la angostura. Con todo, la fantasía ultradefensiva no termina aquí: Juan Bautista Antonelli informa al rey que ha propuesto a la junta "poner una cadena de madera entre las dos fuerzas", sujeta a dos pilares instalados dentro del canal. La cadena

ha de ser de maderos gruesos, con sus eslabones de hierro recios, y en medio sostenido de un par de barcones, por ayudarla a sostentar siempre a un peso sobre el agua. En los cuales barcones podría haber dos cañones o medios que tirasen por el filo del agua, cabe los cuales a un lado se recogerán los demás barcones y emba-

54 Zapatero, 1978, p. 130. Para una completa descripción de este proyecto, ver Segovia Salas, 1996, pp. 47-72.

55 Carta del duque de Alba a Felipe II. Jóbregas, 21-IV-1581. AGS, GM, 112/ 94.

56 La labor de las lanchas cañoneras en el sitio de Gibraltar era proteger a las baterías flotantes. TERRÓN Ponce, 2000, pp. 177-178.

57 O’Scanlan, 1847, p. 221. En su Diccionario Marítimo Español, el autor dice que "fueron inventadas y puestas en uso en España y después las han adoptado las demás naciones”. O’ScANLAN, 1831, p. 330. En el Museo Naval se encuentra un dibujo de Ramón Rivert que conmemora la invención de Barceló. Reproducido por GUARDA, 1990, p. 315.

58 Guarda, 1990, pp. 314-315. 
razarán juntamente con la cadena el pasar adelante; y entretanto el artillería de las fuerzas y barcones tenían tiempo de echarlos a fondo ${ }^{59}$.

La cadena era un elemento común en la defensa de los puertos centroamericanos, aunque se consideraba una protección provisoria ${ }^{60}$. Podemos verla en un plano de La Habana, datado el año 1567, donde se propone la fortificación completa del puerto $^{61}$. Sabemos que en 1593 había, así mismo, una cadena que guardaba la boca del puerto de Santo Domingo ${ }^{62}$. Sin embargo, también experimenta una sofisticación en el proyecto del estrecho: ahora se pondrán dos barcones unidos en medio de ella, bien pertrechados de artillería. Estamos ante un antecedente de las baterías flotantes, arma desconocida en el siglo XVI, y que alcanzó un notable desarrollo, aunque con catastróficas consecuencias, durante el bloqueo de Gibraltar en $1782^{63}$.

Si bien no contamos con las trazas del ingeniero, es posible tener una idea de este nuevo invento por medio de un diseño de Bautista Antonelli, el hermano menor de Juan Bautista, quien sería finalmente señalado para levantar los fuertes del estrecho. Espantado por los contratiempos de la Armada del Estrecho, Bautista se quedó en el Brasil alegando problemas de salud, volviendo a España poco después, donde sería mal considerado por su deserción. Sin embargo, el año 1588 Bautista Antonelli regresa a América en el marco del plan general de fortificación del Caribe ${ }^{64}$. Revisando sus diseños, nos damos cuenta que no había desechado la idea de la cadena y los barcones sugerida al duque de Alba por su hermano mayor, como consta en el diseño que envía a Felipe II en 1591 (Figura 3). Si leemos el texto explicativo, veremos que Bautista perfecciona el uso de los barcones:

Detrás de la cadena, a la parte de dentro se pondrán dos naves viejas de la manera que está señalado, en las cuales se les pondrá dentro mucha brea, alquitrán y pólvora. Y cuado viniese el enemigo a acometer y las naves se allegasen a la cadena entonces se pegará fuego a las dichas naves y d'esta manera se quemarán todos. Porque si acometen este puerto con [viento] norte después que están sobre la boca del puerto, no pueden volver atrás y se han de venir a quemar o dar en la costa ${ }^{65}$.

\footnotetext{
59 Relación que hace Juan Bautista Antonelli sobre los barcones que pareció al duque de Alba se debían hacer entre las dos fuerzas del estrecho. Tomar, 28-IV-1581. AGS, GM, 112/99. Alicia Cámara dice que es posible dudar sobre si fue Juan Bautista o su hermano menor quien asistió a la reunión con la junta en Lisboa (CÁmARA, 2004a, p. 166). Un análisis grafológico de este documento confirma que el autor no es otro que Juan Bautista Antonelli.

60 Gutiérrez, 2005, p. 51.

61 Plano de La Habana, en perspectiva. La Habana, 28-I-1567. AGI, MPD, Santo Domingo, 4.

62 "En esta ciudad tengo hechas para su defensa lo siguiente: una cadena de trozos de viga gruesos con eslabones de yerro que atraviesa la boca del puerto, que no puede entrar ningún navío. Para la defensa de esta cadena hice una casamata a la legua del agua". Carta de Lope de Vega a Felipe II. Santo Domingo, XI-1593. AGS, GM, 379/116.

63 Herrero Fernández-Quesada, 1994, pp. 132-140.

64 Angulo IÑígueZ, 1942, pp. 15-17.

65 Traza de cómo/ se ha de poner la cadena en la/ entrada del puerto de/ La Habana./ Es la segunda, Juan Bautista Antonelli. La Habana, 1591. AGI, MPD, Santo Domingo, 12.
} 
Figura 3. Traza de cómo/ se ha de poner la cadena en la/ entrada del puerto de/ La Habana./ Es la segunda, Juan Bautista Antonelli. La Habana, 1591

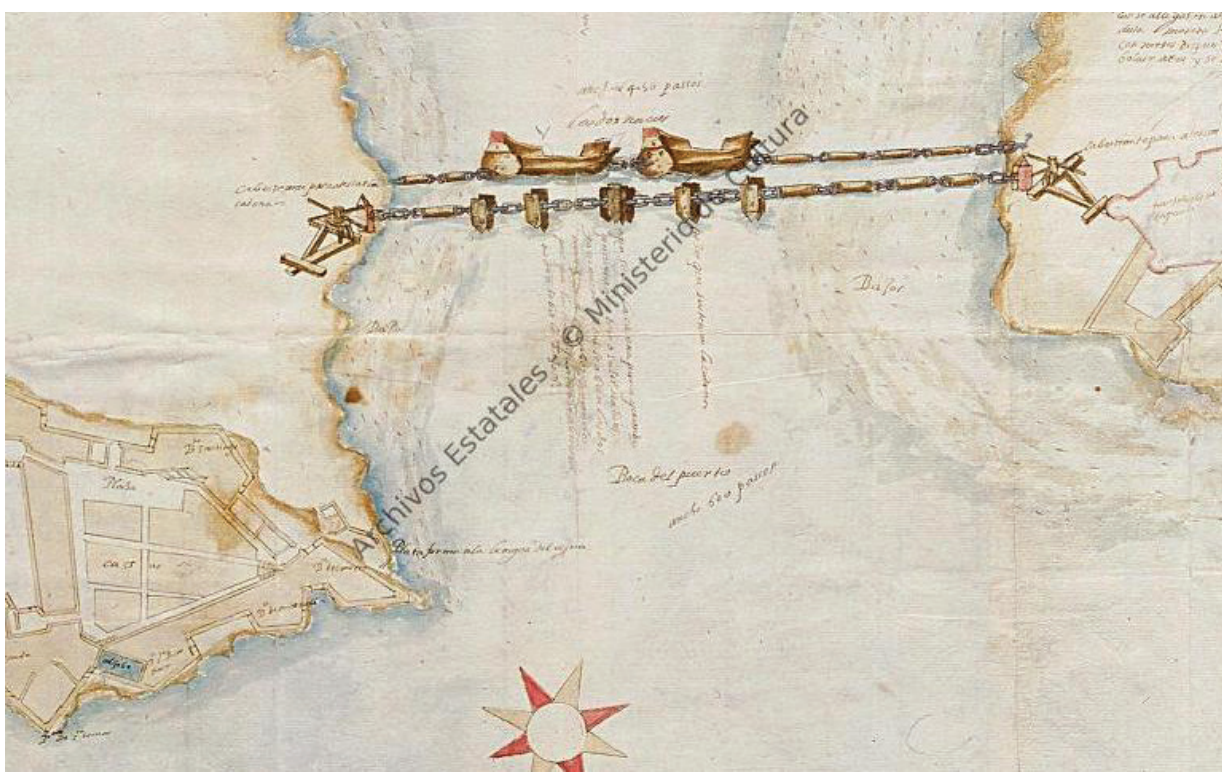

Fuente: AGI, MPD Santo Domingo, 12.

Bautista Antonelli, con esta ingeniosa celada, se apropia del elemento sorpresa que hasta ahora parecía exclusivo de los corsarios. El complejo de defensa del estrecho de Magallanes también estaba prevenido contra el temible factor sorpresa mediante una serie de atalayas que debían informar oportunamente a las fortalezas de la presencia de enemigos, "de manera que los fuertes le tengan con tiempo y estén prevenidos" 66 . Esta solución también responde a un modelo europeo; se pretendió imitar un sistema que estaba dando buenos resultados en la costa mediterránea y en el que también participó la familia Antonelli: una red de atalayas que prevenía de ataques corsarios o berberiscos en el Levante ${ }^{67}$.

\section{OPOSICIÓN AL PROYECTO}

Un proyecto de esta naturaleza no podía carecer de detractores, entre los que destaca la figura de Diego Flores de Valdés, general de la Armada del Estrecho y principal responsable de la realización del sueño futurista del duque de Alba. Sin duda, resulta R. 10.

66 Apuntamiento para la instrucción a Pedro Sarmiento de Gamboa. S.1, 1581. AGI, Patronato, 33, N. 3,

67 CÁmAra, 1991, pp. 79-81. 
placentero inventar nuevos aparatos y tácticas de guerra cuando son otros los encargados de llevarlos a cabo. Flores de Valdés, que tampoco había estado en el estrecho de Magallanes, se opone a casi todos los puntos aprobados por la junta ${ }^{68}$.

El general de la armada desestima los barcones del duque de Alba, proponiendo en su lugar el uso de bergantines. Los barcones le parecían, además de costosos, "tan anchos y tan pesados que no pueden ni sufrirán ninguna vela ni ningún remo" "69. En fin, resultarán ingobernables y torpes, incapaces de hacer frente al viento y corrientes:

las barcas no son navíos competentes ni ligeros para poder seguir ningún navío y lo que el duque de Alba escribe que se ha aprovechado d'ellos y han hecho efeto, esto habrá sido en ríos o esteros muertos donde ningún viento les pueda hacer ningún daño y donde la marea es tan suave que con cualquiera amarra que tenga será bastante para su defensa, lo que no se podrá hacer en el estrecho por ser la corriente tan fuerte y los vientos tan forzosos que aun dudo yo que los navíos de remo se puedan sustentar sino con tiempo de bonanza ${ }^{70}$.

De esta manera, Flores de Valdés pone de relieve las famosas condiciones climáticas del estrecho y de paso deja ver el total desconocimiento de la naturaleza americana por parte del duque de Alba. Cuando se refiere, no sin ironía, a los "ríos o esteros muertos" en que el duque puso a prueba sus inventos bélicos, Flores de Valdés manifiesta que la junta no está en condiciones de evaluar las posibilidades reales de un proyecto fortificador en el estrecho.

Otra de las objeciones de Flores de Valdés es la cadena de Antonelli:

$\mathrm{Y}$ en lo que toca en poner la cadena de un fuerte al otro en dos pilares, esto no se puede hacer en ninguna manera porque los fuertes no han de estar en frente el uno del otro; y no lo estando, no puede servir la cadena. Y para estar en pilares como dice la memoria, y con barcos debajo para sustentarla, al primer tiempo que hubiese-como lo hay cada día en tiempos de invierno- ninguna cosa bastaría a que todo no se desbaratase con la fuerza de la mar y viento. Y la cadena no puede estar sino en puerto cerrado como está en los puertos de la costa de Inglaterra, de un castillo a otro, que la suben y la bajan cuando quieren, pero en parte como el estrecho de ningún efecto será ${ }^{71}$.

Diego Flores de Valdés deja en evidencia que el modelo europeo de fortificación no es válido para el estrecho de Magallanes, que aparece aquí como una frontera prácticamente imposible de dominar. No se trata solo de una diferencia climática importante, sino que hay un problema de escalas: la extensión territorial del estrecho de Magallanes hace que estos inventos parezcan ridículos.

68 A partir de la expedición de Drake se reavivó la discusión respecto de si era preferible fortificar los puertos o establecer un sistema de galeras, con el fin de defender el territorio. LoHMANN VILLENA, 1963, pp. 21-23. Flores de Valdés se había inclinado por la segunda opción, argumentando que era preferible fortificar Lima y Panamá antes que el estrecho de Magallanes. ZaPATERo, 1977, pp. 4-5.

69 Lo que parece a Diego Flores de Valdés que conviene al servicio de su majestad cerca de las seis barcas que se dice son necesarias para la fortificación y fuerza del estrecho de Magallanes. S.1, 4-V-1581. AGS, GM, $113 / 185$.

70 Ibídem.

71 Ibídem 
El general de la armada también se opone a la instalación de las atalayas, diciendo que no serán de ninguna utilidad pues la distancia entre la primera atalaya -a orillas del Atlántico- y angostura es tan considerable que el navío enemigo tendrá tiempo de entrar en el canal antes de que la alarma haya llegado a los fuertes. De nuevo, Flores de Valdés critica la aplicación directa de un modelo de defensa europeo, mediterráneo o británico, ante la desmesura del territorio americano. La mala disposición del general respecto del proyecto fortificador se evidencia en el último párrafo de su memorial: "esto es lo que a mí me parece y cuando fuere necesario dar otros inconvenientes más, bastantes los daré si fueren menester". A pesar esta declaración, concluye: "si a su majestad le parece otra cosa, se cumplirá de la suerte que fuere servido, ordenándolo" "72.

Podemos ver que existen dos posiciones contrapuestas respecto de la defensa del estrecho. Por un lado, se trata de un territorio donde todo es posible, donde las dificultades del terreno se salvan con novedades técnicas. Para Antonelli y el duque de Alba, el estrecho es un espacio de experimentación. Han creado un complejo defensivo que responde a los principios de acumulación, adaptación y mejora de las diferentes técnicas de defensa vigentes en Europa. Flores de Valdés, por el contrario, hace ver las dificultades de la aplicación de los diseños de Antonelli y las ideas del duque, basándose en las duras condiciones climáticas del estrecho y en las enormes distancias que sería necesario controlar para su óptima defensa. Así, el espacio magallánico se mueve entre dos extremos: un lugar en que los sueños bélicos pueden realizarse; pero también, una frontera intelectual que desafía el entendimiento estratégico de los mejores militares de la monarquía ${ }^{73}$.

Hubo un punto muy importante en la discusión sobre la defensa del Pacífico: la geografía magallánica. El debate se centró en la posibilidad de que existieran otros canales que conectasen el Atlántico y el Pacífico. El Consejo de Indias hace saber al rey en 1579 de los inconvenientes de instalar una fortaleza, porque después de haber consultado con cosmógrafos y pilotos, además de revisar relaciones y derroteros de la zona, llega a una conclusión poco auspiciosa: la fortaleza que se proyecta levantar en el estrecho "no se sabe que haya disposición para poderse hacer en parte que impida el paso al enemigo, por entenderse que hay muchas canales de entradas y salidas"74.

Es notable el hecho de que tres memorialistas advirtieran a Felipe II de la necesidad de emprender una cuidadosa exploración de los canales australes antes del tomar la decisión de fortificar. El cosmógrafo Juan Baustista Gesio, luego de hacer una exposición de los cuatro puntos más angostos del estrecho, dice que "no se ha de hacer fuerte en ninguna d'estas cuatro anchuras si primero no se anda el estrecho palmo por palmo, así de la una costa como de la otra para ver si hay otras entradas y salidas por los muchos canales que hace el estrecho"75. Del mismo parecer es Diego

72 Ibídem.

73 La idea del estrecho de Magallanes como frontera geográfica e intelectual fue propuesta por Paul Firbas a partir de su lectura de "Armas antárticas" de Juan de Miramontes Zuárzola. FirbAs, 2003, pp. 141-142.

74 Consulta del Consejo de Indias. Madrid, 26-VIII-1579. AGI, Indiferente, 739, N. 210.

75 Dice que hay que explorar también Tierra del Fuego: "que diligentemente se navegue la costa de la tierra hacia'l Antártico", hasta los 60 latitud sur. Parecer de Juan Bautista Gesio. Madrid, 27-VIII-1579. AGI, Patronato, 33, N. 2, R. 7. 
Robles, quien recalca que "lo primero [es averiguar] si este estrecho tiene más de una canal y entrada y si estando aquel paso guardado, lo estaría la Mar del Sur"76. Otro de los que advirtieron al rey del peligro que estaba asumiendo la Armada del Estrecho fue Cristóbal de Eraso, general de la flota de Indias. Eraso cuestionó seriamente las exploraciones de Sarmiento de Gamboa, que por venir en un solo navío no podía haber realizado una exploración cabal del territorio. Así, expone la posibilidad de que hubiese "muchas bocas y canales y no se pudiese defender el paso a los enemigos" 77 , ante lo cual propone que sea una flota de galeras la encargada de vigilar los canales del sur de América.

A pesar de todas las dudas y cuestionamientos, la preparación de la armada siguió adelante. El proyecto de fortificación sufrió algunas modificaciones, considerando aspectos señalados por Diego Flores de Valdés y los memorialistas mencionados. Así, pese a todo lo tratado en la junta organizada por el duque de Alba, ninguna de las ideas debatidas cuajó en un diseño concreto. Luego de las imágenes visionarias, la cordura pareció apoderarse de los asesores de Felipe II. Para comprender este nuevo vuelco en el proyecto conviene atender a la "Instrucción a Bautista Antonelli", que deja muchos puntos al criterio del ingeniero, diciendo que todo aquello "que aquí no se refiere, se remite a la inteligencia que tenéis" ${ }^{78}$. Esta concesión a la inteligencia podemos interpretarla como una aceptación del enorme desconocimiento que se tenía de la geografía del estrecho en 1581, lo que obligaba a evitar resoluciones que pudieran chocar con la orografía de la zona en el momento de la construcción. De hecho, se encarga a Bautista Antonelli decidir respecto al diseño y emplazamiento de los fuertes luego de un examen detenido del territorio. Sabemos que estas trazas no llegaron a realizarse pues el ingeniero desembarcó en Brasil ${ }^{79}$. En la instrucción vuelve a aparecer el asunto de la cadena propuesta por Juan Bautista Antonelli, quedando, cómo no, a criterio del ingeniero ${ }^{80}$.

\footnotetext{
76 Parecer de Diego Robles. S.1, 1580. AGI, Patronato, 33, N. 3, R. 3.

77 Carta de Cristóbal de Eraso a Felipe II. S.1, 1581. AGI, Patronato, 255, N. 2, G. 1, R. 17 (2).

78 "Elegidos los sitios haréis la traza y planta y montea de cada uno de los dichos fuertes de por sí, considerando la importancia de los efectos que d'ellos se han de hacer y que han de ser capaces de alguna más cantidad de gente de guarnición de la que ahora ha de quedar en ellos, por si adelante fuere necesario ponerla y que sean muy fortalecidos. Y siendo posible estén eminentes, de suerte que descubran y señoreen mar y tierra y tengan buena prespetiva. Y comunicado con el dicho general y demás personas inteligentes que le pareciere lo que de allí se acordare, se porná en relación para que con suma brevedad se haga la obra. Y esto se entienda no se os habiendo dado acá las trazas porque en tal caso se ha de hacer el edificio conforme a ellas, si no fuese por estar los sitios de tal manera que por ello conviniese mudarse en todo o en parte. Y siendo esto así, se os remite para que lo tratéis como más convenga y sea más a propósito". Instrucción a Bautista Antonelli. Lisboa, 12-VIII-1581. AGI, Chile, 165, L. 1, fols.163v-164r.

79 "Dios fue servido de que en la arribada de la isla de Santa Catalina me quebré de un lado y en el fuerte que se hizo en el río de Sanctos me acabé de manera que no soy de ningún efeto y cada día voy empeorando y la mayor parte del tiempo estoy en la cama [...] Yo me quedaré en esta fortificación pues que ahora la ida del estrecho no van a fortificar porque no tienen lo necesario para ello, que'es petrechos y oficiales, así de canteros". Carta de Bautista Antonelli a Felipe II. Río de Janeiro, 31-V-1583. AGS, GM, 145/14.

80 "Y si fuere posible y hubiere buena dispusición para poner cadena del uno al otro para que estorbe el paso del dicho estrecho, se hará así. Y no siendo posible, a lo menos se procurará que sean en tan buenos y convinientes sitios que, con la artillería y fuegos artificiales que en los dichos fuertes ha de haber, no pueda pasar ningún navío sin echarle a fondo". Instrucción a Bautista Antonelli. Lisboa, 12-VIII-1581. AGI, Chile, 165 , L. 1, fols. $163 \mathrm{v}-164 \mathrm{r}$.
} 
Como hemos visto, el proyecto de fortificación pasó por un arduo proceso en el que se enfrentaron distintos conceptos en torno a la defensa del Pacífico, y donde no faltó quien señalara la carencia de información respecto de la geografía americana. Finalmente, la discusión entre Juan Bautista Antonelli, apoyado por la junta; y Flores de Valdés, el Consejo de Indias y los memorialistas, por otro lado, derivó en una suerte de consenso que daba mayor libertad de maniobra al ingeniero responsable de la construcción los fuertes ${ }^{81}$. La advertencia de que el estrecho de Magallanes no era, previsiblemente, el único canal interoceánico, fue considerada al encargar una exploración íntegra de la zona a la Armada del Estrecho ${ }^{82}$.

\section{IMAGEN DE LA MONARQUÍA}

Cabe preguntarse por los motivos que llevan a Felipe II a decidirse por una opción tan costosa y arriesgada como la fortificación del estrecho, tomando en cuenta todos los problemas logísticos que suponía una acción de este tipo, el desconocimiento de la geografía austral americana y las muchas voces que se opusieron a la consecución de un proyecto tan raro y ambicioso. Consideremos, sin ir más lejos, que la empresa se vería claramente comprometida de haber otros canales que conectasen los dos océanos o si finalmente Tierra del Fuego resultase ser una isla ${ }^{83}$.

Podemos suponer que las evidentes falencias del proyecto fortificador quedaron opacadas ante la grandiosa visión de los fuertes en el estrecho. El rey y su entorno inmediato fueron deslumbrados ante la idea de construir una fortaleza inexpugnable en los confines del mundo conocido. Felipe II, en un gesto de potencia y majestad, intenta manipular la geografía americana y poner un cerrojo allí donde parece imposible. Esta era, sin duda, una obra digna del mayor rey del mundo. Sarmiento de Gamboa califica la misión de la Armada del Estrecho como una obra "heroica y azarosa" y dice que el rey hace y hará "de tal orden que'l demonio quede corrido y los infieles admirados y acobardados" $" 84$.

Así, debemos incluir el proyecto de fortificación en la enorme maquinaria propagandista de los Austrias. No resulta descabellado comparar el proyecto magallánico con una obra tan reconocida como el monasterio del Escorial, un palacio diseñado para celebrar la grandeza y gloria de la monarquía y proyectar una imagen de majes-

81 Hay un documento que recoge algunos de los puntos señalados por Flores de Valdés: Apuntamiento para la instrucción a Pedro Sarmiento de Gamboa. S.1, 1581. AGI, Patronato, 33, N. 3, R. 10.

82 "Y llegado que seáis a él, habiéndole todo reconocido con gran vigilancia y cuidado, haréis en la parte más angosta y conveniente dos fuertes". Instrucción del rey a Diego Flores de Valdés. Tomar, 1-V-1581. AGI, Patronato, 33, N. 3, R. 5.

83 Esta posibilidad ya se había planteado en 1554, cuando Jerónimo de Alderete proponía la construcción de un fuerte en el estrecho de Magallanes: "según la noticia que se tiene, aunque el estrecho se pueble y se hagan fortalezas en él, del un cabo y del otro, no se podrá prohibir que no se navegue y pasen navíos por él, sabiéndose el pilotaje y la navegación. Y demás desto la tierra que está de la otra parte del estrecho podría ser que fuere isla, y descubriéndose y bojándose la navegación, estaría libre para se navegar la Mar del Sur y sería cosa superflua haber hecho fortalezas para prohibir la entrada del estrecho". Consulta del Consejo de Indias. Valladolid, 15-XII-1554. AGI, Indiferente, 737, N.108.

84 Carta de Pedro Sarmiento de Gamboa a Felipe II. Cádiz, 14-10-1581. AGS, GM, 118/149. 
tad digna del templo de Salomón ${ }^{85}$. La fortaleza del estrecho, tal como fue concebida por el duque de Alba, Pedro Sarmiento y Antonelli, llevaría el nombre de Felipe II a los límites del mundo: se trata, a su vez, de un acto que ningún monarca en la historia de la humanidad había soñado hacer. La unión dinástica de España y Portugal sería celebrada por todo lo alto con una construcción de gran envergadura, digna de la nueva monarquía hispánica. Felipe II quiere entrar en los anales de la historia mediante una obra monumental, encargada de representar el poder del rey católico y el avance técnico de un imperio con clara vocación global.

Los planes del duque de Alba y la junta revelan la intención de la monarquía hispánica respecto del paso austral: no se trata solo de defenderse sino de aterrorizar al enemigo. El aparato defensivo: fuertes, barcones, cadena, están allí para enviar un potente mensaje disuasivo ${ }^{86}$. El concepto de fortaleza como teatro bélico al que se refieren los estrategas del siglo XVIII ${ }^{87}$ alcanza en este proyecto una dimensión que excede las perfecciones puramente técnicas: se trata de la preparación, en el confín del mundo, de una puesta en escena inolvidable, un auténtico espectáculo de la guerra. De esta manera, se logrará exhibir un poder destructor implacable contra quienes se atreviesen a desafiar la autoridad real. Las fortalezas soñadas por el duque de Alba estaban destinadas a entrar en el imaginario bélico del siglo XVI y propiciar un símbolo de monarquía inexpugnable, con la capacidad de dividir el mundo en dos mitades, empleando la ingeniería más sofisticada de su tiempo. Estamos ante un proyecto que necesita innovaciones nunca vistas: el secreto propósito de sus artífices era levantar un complejo defensivo que valiese la admiración de los enemigos de España y restituyese la mermada reputación del rey ante los insultos de Francis Drake e Isabel Tudor; una fortaleza cuyo destino era convertirse en un retrato perenne del poder monárquico.

\section{CONCLUSIONES}

Es necesario hacer una revisión de las fuentes conocidas y proponer una discusión en torno a las nuevas fuentes documentales. Es conveniente, además, con el objetivo de avanzar en la investigación de este proyecto, emprender un rastreo de documentos en archivos y bibliotecas de Europa y América. Sin duda, será muy oportuno hacer una labor de edición de estos materiales ${ }^{88}$.

\footnotetext{
85 Rincón Álvarez, 2007, pp. 171-181.

86 La fortificación, en cuanto representación de poder, es una elocuente forma de comunicación entre gobernantes, "se convertía así en un arma política que provocaba recelos, podía resultar amenazadora, podía informar sin palabras de que un equilibrio político entre dos estados estaba cambiando". CÁMARA, 1998, p. 59. En 1582, el gobernador Carreño comentaba que el castillo de la Real Fuerza de La Habana "solo con la fama hacía la guerra". GuTIÉRREZ, 2005, p. 123.

87 El ingeniero "dominará las 'trazas', la geometría proporcionada y regular que parece llevar a las tácticas ofensivas de los sitiadores, a planteamientos bélicos de puro cálculo, puesto que los asaltos se habrían de resolver en problemas de líneas, ángulos, fosos, bermas y cunetas. Es decir, quedaba 'a priori' formalizado un escenario que con razón, los estrategas del siglo XVIII vinieron a denominar "teatro bélico"'. ZAPATERo, 1978, p. 12.

88 Por mi parte, preparo una edición crítica de la Sumaria relación de Pedro Sarmiento de Gamboa, donde incluyo algunos textos inéditos relacionados con la Armada del Estrecho.
} 
En definitiva, el proyecto de fortificación del estrecho de Magallanes, el año 1581, fue uno de los sueños bélicos más ambiciosos e innovadores del reinado de Felipe II, un rey que fue considerado, en su tiempo, experto en arquitectura pública, "la que se convierte en imagen política del poder" ${ }^{\prime 9}$. Como hemos visto, en el siglo XVI no existían los medios técnicos para llevar a cabo una obra semejante y de ahí que el proyecto plantease una visión futurista del todavía incipiente arte de la fortificación. Es palpable la total confianza en las posibilidades de la técnica defensiva y en la capacidad logística de la armada española, encargada de trasladar soldados, pobladores, bastimentos, artillería, hierro y herramientas hasta el estrecho.

Como se desprende de los textos citados, el enemigo a vencer, en última instancia, es la geografía americana. Las fortalezas demuestran una sed de dominio del espacio, la ambición de establecer un control total sobre el Pacífico. El estrecho de Magallanes se transforma en una solución de continuidad para el comercio y la seguridad de las colonias. Se trata de una respuesta genial ante la imposibilidad de cerrar el territorio a los enemigos de España.

\section{REFERENCIAS BIBLIOGRÁFICAS}

Angulo IÑígueZ, Diego

1942 Bautista Antonelli. Las fortificaciones americanas del siglo XVI. Madrid. Hauser y Menet.

Arciniega, Rosa

1956 Pedro Sarmiento de Gamboa (el Ulises de América). Buenos Aires. Editorial Sudamericana.

BArros, José Miguel

2006 Pedro Sarmiento de Gamboa. Avatares de un caballero de Galicia. Santiago de Chile. Editorial Universitaria.

Benites, María Jesús

2004 "Con la lanza y con la pluma”. La escritura de Pedro Sarmiento de Gamboa. Tucumán. Instituto Interdisciplinario de Estudios Latinoamericanos - Universidad del Tucumán.

Bouza Álvarez, Fernando

1987 Portugal en la monarquía hispánica (1580-1640). Felipe II, las Cortes de Tomar y la génesis del Portugal Católico. Madrid. Editorial de la Universidad Complutense de Madrid. Vols. I y II.

Braun Menéndez, Armando

1969 Pequeña historia magallánica. Buenos Aires. Francisco de Aguirre.

CÁmARA, Alicia

1988 "Tiburcio Spannocchi, ingeniero mayor de los reinos de España". Revista de la Facultad de Geografía e Historia. Madrid. Universidad Nacional de Educación a Distancia, $\mathrm{n}^{\mathrm{o}} 2$, pp. 77-90.

1991 "Las torres del litoral en el reinado de Felipe II: una arquitectura para la defensa del territorio (y II)". Espacio, tiempo y forma. Madrid, Serie 7, tomo 4, pp. 53-94.

89 CÁmara, 2004b, p. 163. 
1998 Fortificación y ciudad en los reinos de Felipe II. Madrid. Editorial Nerea.

2004a "Giovanni Battista Antonelli e la definizione professionale dell'ingegnere nel Rinascimento spagnolo". En SARTOR, Omagio agli Antonelli. Udine:. Forum, pp. 164-198.

2004b "La profesión de ingeniero: los ingenieros del rey". En SuÁREz, Técnica e ingeniería en España I. El Renacimiento. Zaragoza. Institución "Fernando el Católico" - Prensas Universitarias - Real Academia de la Ingeniería.

Cruz Almeida, José

2010 “Grandes viajes en el mundo hispánico, nuevos mapas”. En Cuesta Domingo - SurroCa Carrascosa, Cartografia hispánica. Imagen de un mundo en crecimiento. 15031810. Madrid. Ministerio de Defensa, pp. 201-219.

De la Fuente, Pablo

2004 “El capitán Fratín y la Real Casa de Munición de Guerra de Rosas: un ejemplo de arquitectura militar". AIEE. Figueres, n³7, pp. 97-109.

De Nigris, Mariana E. - SenAtore, María Ximena

2008 “Arqueología histórica en los confines del imperio. La ciudad del Nombre de Jesús (estrecho de Magallanes, siglo XVI). Telar. Tucumán, nº, pp. 129-144.

FERNÁNDEZ DE NAVARRETE, Martín

1971 Colección de documentos y manuscriptos compilados por Fernández de Navarrete. Liechtenstein. Kraus-Thomson Organization Limited, vol. 20, part one, pp. 267-272.

FIRBAS, Paul

2003 "Fracaso, derrota y épica: las poblaciones del estrecho de Magallanes (1984-1977)". Iberoromania. Berlín, $\mathrm{n}^{\circ}$ 58, pp.126-137.

Galende Díaz, Juan Carlos

1998 "La escritura humanística en la Europa del Renacimiento". Espacio, tiempo y forma. Madrid, Serie III, nº 11, pp. 187-230.

GuARDA, Gabriel

1990 Flandes indiano. Las fortificaciones del reino de Chile. 1541-1826. Santiago de Chile.; Ediciones Universidad Católica de Chile.

GuILLÉN TATO, Julio

1942 Monumenta cartographica indiana. Regiones de la Plata y magallánica. Madrid. Ministerio de Asuntos Exteriores.

1944 Colección de diarios y relaciones para la historia de los viajes y descubrimientos. Madrid. Instituto Histórico de la Marina. Vol. III

GuTIÉRREZ, Ramón

2005 Fortificaciones en Iberoamérica. Madrid. El Viso.

HAKLUYT, Richard

1935 The original writings and correspondance of the two Richard Hakluyt [1568-1616].

TAYLOR (ed.). Londres. The Hakluyt Society. Vol. I.

Hernando SÁnchez, Carlos José

2001 "Saber y poder. La arquitectura militar en el reinado de Carlos V". En Hernando SánCHEZ, Las fortificaciones de Carlos V. Madrid. Ediciones del Umbral, pp. 21-91.

Herrero Fernández-QuesadA, María Dolores

1994 “La artillería en la guerra contra la convención”. En VALdÉs SÁnCHEZ, Al pie de los cañones. La artillería española. Madrid. Tabapress, pp. 147-177.

Kelsey, Harry

1998 Sir Francis Drake. The Queen's Pirate. New Haven, Yale University Press. 
LANDín CARRasco, Amancio

1945 Vida y viajes de Pedro Sarmiento de Gamboa. Madrid. Instituto Histórico de la Marina.

LOHMANN ViLLENA, Guillermo

1963 "Las defensas militares de Lima y Callao hasta 1746". Anuario de Estudios Americanos, Sevilla, n 20, pp. 1-217.

MARTINIC, Mateo

1977 Historia del estrecho de Magallanes. Santiago de Chile. Andrés Bello.

1983 "El reino de Jesús. La efímera y triste historia de una gobernación en el estrecho de Magallanes (1581-1590)". Anales del Instituto de la Patagonia. Punta Arenas, nº 14, pp. 7-32.

1992 Historia de la región magallánica. Santiago de Chile. Universidad de Magallanes, vol. I.

Nussio DíAz, Eduardo

1999 "El infructuoso regreso de Pedro Sarmiento de Gamboa al estrecho de Magallanes". En Cuesta Domingo, Descubrimientos y cartografía en la época de Felipe II. Valladolid. Seminario Iberoamericano de Descubrimientos y Cartografía - Instituto de Estudios de Iberoamérica y Portugal, pp. 241-263.

2001 "Vida y viajes de Pedro Sarmiento de Gamboa". En Varela Marcos, Descubrimientos y cartografía IV: grandes viajes descubridores. Valladolid. Seminario Iberoamericano de Descubrimientos y Cartografía - Instituto Interuniversitario de Estudios de Iberoamérica y Portugal, pp. 165-287.

O’Donnell, Hugo

1992 España en el descubrimiento, conquista y defensa del mar del Sur. Madrid. Mapfre.

O'Scanlan, Timoteo

1831 Diccionario Marítimo Español. Madrid. Imprenta Real.

1847 Cartilla práctica del constructor naval. Madrid. Imprenta Nacional.

OYARZÚN IÑARRA, Javier

1976 Expediciones españolas al estrecho de Magallanes y Tierra del Fuego. Madrid. Ediciones Cultura Hispánica.

PARKER, Geoffrey

1998 La gran estrategia de Felipe II. Madrid. Alianza.

2010 Felipe II. La biografía definitiva. Barcelona. Planeta.

Rincón Álvarez, Manuel

2007 Claves para comprender el Monasterio de San Lorenzo de El Escorial. Salamanca.

Ediciones Universidad de Salamanca.

SANTOS, Ricardo Evaristo dos

1993 El Brasil filipino. Madrid. Mapfre.

SARmiento de Gamboa, Pedro

1950 Viajes al estrecho de Magallanes [1572-1592]. Rosenblat (ed.). Buenos Aires. Emecé. vol. I y II.

1988 Viajes al estrecho de Magallanes [1580-1590]. SARAVIA VIEJo (ed). Madrid. Alianza.

SCHÄFER, Ernest

1935 El Consejo Real y Supremo de las Indias. Sevilla. Imprenta Carmona. Vol. I y II. 
Segovia Salas, Rodolfo

1996 Las fortificaciones de Cartagena de Indias. Estrategia e historia. Bogotá. El Áncora.

SOROMENHO, Miguel

2004 "Il Portogallo nella monarchia iberica: i percorsi di Giovanni Battista Antonelli". En SARtor, Omagio agli Antonelli. Udine. Forum, pp. 263-273.

Tellechea Idígoras, José Ignacio

1988 Otra cara de la Invencible. La participación vasca. San Sebastián. Sociedad Guipuzcoana de Ediciones y Publicaciones.

Terrón Ponce, José Luis

2000 El gran ataque a Gibraltar de 1782: análisis militar, político y diplomático. Madrid. Ministerio de Defensa.

VALLADARES, Rafael

2008 La conquista de Lisboa: violencia militar y comunidad política en Portugal, 15781583. Madrid. Marcial Pons.

Viganò, Marino

2004 “El Fratín mi inginiero". Bellinzona. Casagrande.

ZAPATERo, Juan Manuel

1977 "El Castillo del Real Felipe del Callao". Anuario de Estudios Americanos. Sevilla, no 34, pp. 703-733.

1978 La fortificación abaluartada en América. Barcelona. Instituto de la Cultura Puertorriqueña. 